\title{
Factors Affecting Visual Outcome Following Surgical Treatment of Cataracts in Children
}

\author{
Mehul A. Shah, Shreya M. Shah, Khushboo A. Shikhangi, Pramod R. Upadhyay, Geetopam B. Bardoloi
}

Drashti Netralaya, Dahod, India.

Email: omtrust@rdiffmail.com

Received August $8^{\text {th }}, 2012$; revised September $14^{\text {th }}, 2012$; accepted October $30^{\text {th }}, 2012$

\begin{abstract}
Purpose: To assess treatment results in pediatric patients with cataracts, to evaluate the efficacy of various surgical interventions, and to determine the factors that affect visual outcomes. Methods: This is aProspective cohort study. We studied a consecutive series of pediatric patients with congenital, developing, or traumatic cataracts who underwent surgery between January, 1999 and April, 2012 at Drashti Netralaya, Dahod. Patient demographics, cataract type, presenting symptoms, surgical intervention, postoperative visual acuity, and follow-up refractive changes were recorded. Results: In total, 1305 eyes of 1047 children were included: unilateral cataracts were present in $786(60.2 \%)$ eyes. There were $610(46.7 \%)$ traumatic and 695 (53.3\%) non-traumatic cases. Ages at surgery ranged from 1 to 215 months. Eyes were grouped by the surgical intervention performed: Group 1, pars plana approach including $366(28 \%)$ eyes that underwent lensectomies, and Group 2, anterior approach, including 939 (71.9\%) eyes that underwent phacoemulsification \pm IOL placement or small incision cataract surgery \pm IOL placement. The mean follow-up time was 117 days. Ultimately, $113(30.9 \%)$ Group 1 and $503(53.6 \%)$ Group 2 patients achieved a visual acuity better than 20/60 $(P<$ 0.001). Age at intervention, laterality, sensory nystagmus, pre-treatment vision, IOL insertion, and etiology were all significantly related (all $P<0.001$ ) to visual outcome. Conclusions: Surgical treatment with intraocular lens implantation for children with congenital, developmental, or traumatic cataracts is an effective treatment for visual rehabilitation. Visual outcome was significantly better in cases of traumatic cataracts versus non-traumatic cataracts.
\end{abstract}

Keywords: Pediatric Cataract; Visual Outcome; Traumatic Cataract; Developmental Cataract; Congenital Cataract

\section{Introduction}

Childhood cataracts are responsible for $5 \%-20 \%$ of blindness in children worldwide and for an even higher percentage of childhood visual impairment in developing countries [1-5]. The overall incidence of clinically significant cataracts (unilateral or bilateral) in childhood is unknown, but has been estimated to be as high as $0.4 \%$ $[6,7]$. The prevalence of childhood cataract varies from 1.2 to 6.0 cases per 10,000 infants. Pediatric cataracts are responsible for more than one million cases of childhood blindness in Asia. In developing countries, such as India, $7.4 \%-15.3 \%$ of childhood blindness is due to cataracts $[8,9]$. Internationally, the incidence is unknown. Although the World Health Organization and other health organizations have made outstanding progress in vaccination and disease prevention, the rate of congenital cataracts remains much higher in underdeveloped countries.

The visual results of cataract surgery in children have generally [10-12] been poorer than in adults [1-3, $6,12,13]$. This difference is due, in part, to the various types of amblyopia that develop in children with cata- racts, the association of nystagmus with early onset cataracts, and the presence of other ocular abnormalities that adversely affect vision in eyes with developmental lens opacities. Since the introduction of the aspiration technique for cataract removal by Scheie in 1960 [14], surgical procedures for the removal of the lens in childhood have improved $[15,16]$, and earlier surgery for congenital cataracts has been encouraged [17-19].

Any opacification of the lens and its capsule in children is defined as a pediatric cataract. Pediatric cataracts can be unilateral or bilateral. They can be subdivided based on morphology, as well as etiology. Morphologically, the most common type of pediatric cataract is the zonular cataract, characterized by opacification of a discrete region of the lens. This type includes nuclear, lamellar, sutural, and capsular cataracts $[6,10]$.

Polar cataracts are opacities of the subcapsular cortex in the polar regions of the lens. Almost all $(90 \%)$ anterior polar cataracts are unilateral; bilateral anterior polar cataracts are commonly asymmetric and typically do not progress over time. Posterior polar cataracts are often 
small, but even a small posterior polar cataract can impair vision. A distinctive type of posterior polar cataract is the posterior lentiglobus or lenticonus, in which a protrusion of the posterior capsule is present. Membranous cataracts form when the lens, cortex, and nucleus are partially or completely reabsorbed, leaving a small amount of opacified lens material between the anterior and the posterior lens capsules (Duke-Elder, 1972).

Congenital cataracts are one of the most common causes of treatable blindness in children, particularly in developing countries [1]. A recent report indicated that infants with bilateral congenital cataract who underwent early surgery (within 1 month of birth) and received appropriate optical rehabilitation could obtain visual acuity of better than 0.4 and could even achieve stereopsis [2]. However, because of typically relatively late detection and diagnosis, the nonavailability of facilities for infant anesthesia, and poor compliance with long-term followup, the visual prognosis for infants with congenital cataract in developing countries differs markedly from that in industrialized countries. Visual loss is primarily attributable to amblyopia, most importantly, to "stimulus-form deprivation amblyopia," with the additional factor of ocular rivalry in unilateral disease. Thus, improved understanding of the critical periods of visual development has resulted in to surgical intervention for dense cataracts being deemed necessary within the first 3 months of life, possibly as early as the first 6 weeks in unilateral disease. Clinical factors believed to be important to visual outcome in children include age at diagnosis and surgery, type of refractive correction, type of cataract surgery, compliance with occlusion regimen, etiology of the cataract, presence of non-ophthalmic disorders, development of capsular opacity or secondary membrane, and serious ocular postoperative complications.

Primary posterior capsulotomy and anterior vitrectomy are considered "routine surgical steps," especially in younger children. Previously, preparation for secondary intraocular lens (IOL) implantation at a later date was not considered. However, widespread acceptance of IOL implantation in children has caused this to be revised. Thus, management of the posterior capsule should eliminate or delay the formation of visual axis opacity and yet leave sufficient capsular support to achieve the desired "inthe-bag" (or ciliary sulcus) fixation of an IOL. Even when IOL implantation is not performed with the primary procedure, it is important to treat and prepare the eye in such a way that secondary implantation can be achieved subsequently.

\section{Materials and Methods}

The study was approved by the hospital ethics committee. This was a prospective hospital-based study at a tertiary care eye hospital in western India over 20 years, from January, 1992 to April, 2012. All pediatric patients (0 to 18) with cataracts presenting to our department during this period were enrolled in the study.

Patient primary details and history were documented using a pre-tested online format. Ocular trauma details were documented with an online world eye injury registry form.

Vision was checked according to the American Academy of Pediatrics vision check protocol. Both eyes were assessed. Anterior segment examinations were conducted using a slit lamp bio-microscope. The pupils were dilated.

Ocular pressure was measured using a Perkin's handheld tonometer. If this was not possible, the pressure was measured under general anesthesia. This procedure was omitted for eyes with open globe injuries. The posterior segment of the eye was evaluated with the help of an indirect ophthalmoscope and a $+20 \mathrm{D}$ lens and an ultrasound "B" scan if the media was not clear.

The surgical technique was decided based on etiology, cataract morphology, and the position of the lens. Surgery was done by the anterior or pars plana route. Anterior route surgeries were performed using a phacoemulsifier or manual suction. Membranectomies and lensectomies were performed using a pneumatic cutter leaving capsular support for secondary implant. Intraocular lenses were not implanted in patients younger than 1.5 years. Children below this age underwent lensectomies/membranectomies; secondary implant placement was conducted later. Patients were rehabilitated using glasses or contact lenses in-between. For IOL power calculations, we followed published guidelines [20,21].

In cases of globe rupture, open globe injury wound repair was done as a first stage and the cataract was operated on at a second sitting. All steps of the surgical techniques were documented using a pretested online format.

All traumatic cataract patients without infection were treated with systemic corticosteroids. In all patients with inflammation and membranous cataracts, a primary posterior capsulotomy and anterior vitrectomy were performed.

Postoperative follow-up was performed according to a pretested online format, including vision, anterior and posterior segment findings and intra ocular pressure, over an appropriate follow-up schedule. Glasses were prescribed when the media were clear and the final prescription was at 6 weeks post-operation. Patients underwent orthoptic evaluations and amblyopic patients were treated with appropriate patching. Aphakic patients were rehabilitated using glasses or contact lenses. Patients were evaluated for stereopsis and contrast sensitivity using a Titmus vision tester or a Titmus fly test. 
Patients developing later cataracts underwent membranectomies and vitrectomies as required. For children operated on below the age of 1.5 years, secondary lens implantation was performed after they reached 1.5 years of age.

Data were analyzed using the SPSS software (ver. 19.0; SPSS Inc., Chicago, IL, USA). Univariate parametrical analyses were used. A $P$-value of $<0.05$ was considered to indicate statistical significance.

\section{Results}

The enrolled patient group consisted of 1305 eyes in 805 pediatric patients with cataracts. There were $858(65.7 \%)$ males and $447(34.3 \%)$ females (Table 1). The mean patient age was $9.5 \pm 4.7$ years (range, $0-18$ ). Of the cataracts, $610(46.7 \%)$ were traumatic and $695(53.3 \%)$ were congenital or developmental. Of the eyes, 1117 (85.6\%; Table 2) had diminished vision and 188 (14.4\%) presented with leukocoria. The follow-up period was 1 3084 days (mean, 117.4 days).

In the non-traumatic group, eyes were further subdivided into congenital (293, 22.5\%), developmental (373, $28.6 \%$ ), and secondary cataracts (29, 2.2\%; Tables 2 and 3). According to the statistical analysis, the demographic factors analyzed, including socioeconomic status $(74.5 \%$ were of lower socioeconomic status) and residence (92\% were from rural areas), had no significant relationship with the final visual acuity.

Regarding patient entry, $9.2 \%$ of the patients had received primary treatment prior to reaching our center; this was not associated with a significant difference in the final visual outcome $(P=0.2)$. Of the total patients enrolled, $26.4 \%$ entered via an outreach department, and $71 \%$ were self-referred.

Among the injuries, 30\% were reported within the first $24 \mathrm{~h}, 30 \%$ were reported within 3 days, and $33.9 \%$ were reported within 1 month. A wooden stick was the most common object causing eye injury (51.4\%). Neither the injury-causing object $(P=0.3)$ nor the activity at the time of injury $(P=0.3)$ was significantly associated with the final visual acuity.

A comparison of pre- and post-operative visual acuities showed that treatment significantly improved visual acuity (Table 4; $P<0.001$, Pearson's $\chi^{2}$ test; $P=0.001$, ANOVA). An intraocular lens was implanted in 1205 cases $(92.3 \%)$ and was significantly associated with improved visual acuity $(P<0.001)$.

When we compared visual outcome between the traumatic and non-traumatic groups, the traumatic group did significantly better (Table 5; $P<0.001$ ). Final visual acuity following cataract surgery was $>6 / 60$ in 399 eyes $(56.8 \%)$ and $\geq 6 / 12$ in 105 eyes $(15.1 \%)$ in the non-traumatic group. In the traumatic group, the visual acuity
Table 1. Age and sex distribution.

\begin{tabular}{ccc}
\hline \multirow{2}{*}{ Age (Years) } & \multicolumn{2}{c}{ Sex } \\
\cline { 2 - 3 } & Female & Male \\
\hline 0 to 2 & 37 & 56 \\
3 to 5 & 67 & 119 \\
6 to 10 & 156 & 293 \\
11 to 18 & 187 & 390 \\
Total & 447 & 858 \\
\hline
\end{tabular}

Table 2. Aetiology of cataract.

\begin{tabular}{ccc}
\hline Type of Cataract & Frequency & Percent \\
\hline Complicated & 29 & 2.2 \\
Congenital & 293 & 22.5 \\
Developmental & 373 & 28.6 \\
Traumatic & 610 & 46.7 \\
Total & 1305 & 100.0 \\
\hline
\end{tabular}

was $>6 / 60$ in 333 eyes $(54.6 \%)$ and $\geq 6 / 12$ in 193 eyes $(31.6 \%)$. The difference between the groups was significant $(P<0.001)$. In total, $296(22.6 \%)$ eyes had a final visual acuity $\geq 6 / 12$ and $728(57.8 \%)$ eyes had a final visual acuity $>6 / 60$ (Table 5 ).

Sensory nystagmus was present in 221 (17\%) eyes. This caused a significant difference in final visual outcome (Table 6; $P<0.001$ ).

We examined unilateral versus bilateral cataracts (Table 7; $P<0.001$ ) and found better results in unilateral cases. In the non-traumatic group, bilateral cases had better results (Table 7; $P<0.001$ ).

We compared visual outcome according to age of intervention. Significantly better results were achieved in the age range between 6 and 18, likely because of the traumatic cases in this age group (Table 8; $P<0.001$ ).

We compared final visual outcome between the anterior and pars plana routes. An anterior approach resulted in a better outcome (Table 9; $P<0.001$ ).

We also studied visual outcome when a primary posterior capsulotomy and vitrectomy were performed. Primary posterior capsulotomy and vitrectomy were performed in $460(34.5 \%)$ cases and a significant difference was found (Table 10; $P<0.001$ ). Better overall results were achieved if a primary posterior capsulotomy and vitrectomy were not performed, while vision was improved in cases of traumatic cataracts (Table 10; $P=$ 0.008).

Insertion of an IOL resulted in a significant improvement in visual outcome. (Table 11; $P<0.001$ ). 
Table 3. Comparision of visual outcome according to aetiology.

\begin{tabular}{|c|c|c|c|c|}
\hline \multirow{2}{*}{ Visual Acuity } & \multicolumn{4}{|c|}{ Type of Cataract } \\
\hline & Complicated & Congenital & Developmental & Traumatic \\
\hline Uncooperative & 0 & 9 & 6 & 5 \\
\hline$<1 / 60$ & 20 & 66 & 66 & 201 \\
\hline $1 / 60$ to $3 / 60$ & 3 & 61 & 65 & 69 \\
\hline $6 / 60$ to $6 / 36$ & 2 & 17 & 50 & 46 \\
\hline $6 / 24$ to $6 / 18$ & 3 & 128 & 92 & 94 \\
\hline $6 / 12$ to $6 / 9$ & 0 & 5 & 30 & 53 \\
\hline $6 / 6$ to $6 / 5$ & 1 & 5 & 62 & 140 \\
\hline Total & 29 & 291 & 371 & 608 \\
\hline
\end{tabular}

$P=0.0001299$.

Table 4. Comparision of visual outcome according to pre operative visual acuity.

\begin{tabular}{|c|c|c|c|c|c|c|c|}
\hline \multirow{2}{*}{ Visual Acuity (Post OP) } & \multicolumn{7}{|c|}{ Visual Acuity (Preoperative) } \\
\hline & Uncooperative & $<1 / 60$ & $1 / 60$ to $3 / 60$ & $6 / 60$ to $6 / 36$ & $6 / 24$ to $6 / 18$ & $6 / 12$ to $6 / 6$ & $6 / 9$ to $6 / 6$ \\
\hline Uncooperative & 7 & 13 & 0 & 0 & 0 & 0 & 0 \\
\hline$<1 / 60$ & 7 & 321 & 11 & 11 & 3 & 1 & 0 \\
\hline $1 / 60$ to $3 / 60$ & 1 & 128 & 54 & 11 & 5 & 0 & 0 \\
\hline $6 / 60$ to $6 / 36$ & 0 & 74 & 28 & 10 & 3 & 0 & 0 \\
\hline $6 / 24$ to $6 / 18$ & 7 & 132 & 37 & 99 & 41 & 0 & 2 \\
\hline $6 / 12$ to $6 / 9$ & 1 & 62 & 15 & 3 & 7 & 1 & 0 \\
\hline $6 / 6$ to $6 / 5$ & 5 & 140 & 24 & 23 & 12 & 3 & 3 \\
\hline Total & 28 & 870 & 169 & 157 & 71 & 5 & 5 \\
\hline
\end{tabular}

$P=0.000$.

Table 5. Comparision of visual outcome amongst traumatic and non traumatic group.

\begin{tabular}{ccc}
\hline \multirow{2}{*}{ Visual Acuity } & \multicolumn{2}{c}{ Cataract } \\
\cline { 2 - 3 } & Non Traumatic & Traumatic \\
\hline Uncooperative & 15 & 5 \\
$<1 / 60$ & 153 & 201 \\
$1 / 60$ to $3 / 60$ & 130 & 69 \\
$6 / 60$ to $6 / 36$ & 70 & 46 \\
$6 / 24$ to $6 / 18$ & 224 & 94 \\
$6 / 12$ to $6 / 9$ & 36 & 53 \\
$6 / 6$ to $6 / 5$ & 69 & 140 \\
Total & 697 & 608 \\
\hline
\end{tabular}

$P=0.000$.
Table 6. Comparision of visual outcome according to presence of sensory nystegmus.

\begin{tabular}{ccc}
\hline \multirow{2}{*}{ Visual Acuity } & \multicolumn{2}{c}{ Sensory_Nystagmus } \\
\cline { 2 - 3 } & No & Yes \\
\hline Uncooperative & 13 & 7 \\
$<1 / 60$ & 302 & 52 \\
$1 / 60$ to $3 / 60$ & 150 & 49 \\
$6 / 60$ to $6 / 36$ & 96 & 20 \\
$6 / 24$ to $6 / 18$ & 230 & 88 \\
$6 / 12$ to $6 / 9$ & 88 & 1 \\
$6 / 6$ to $6 / 5$ & 204 & 5 \\
Total & 1083 & 222 \\
\hline
\end{tabular}

$P=0.000$. 
Table 7. Comparision of visual outcome according to laterility.

\begin{tabular}{ccc}
\hline \multirow{2}{*}{ Visual Acuity } & \multicolumn{2}{c}{ Laterality } \\
\cline { 2 - 3 } & Bilateral & Unilateral \\
\hline Uncooperative & 8 & 12 \\
$<1 / 60$ & 75 & 278 \\
$1 / 60$ to $3 / 60$ & 98 & 100 \\
$6 / 60$ to $6 / 36$ & 58 & 57 \\
$6 / 24$ to $6 / 18$ & 187 & 130 \\
$6 / 12$ to $6 / 9$ & 28 & 60 \\
$6 / 6$ to $6 / 5$ & 59 & 149 \\
Total & 513 & 786 \\
\hline
\end{tabular}

$P=0.000$.

Table 8. Comparision of visual outcome according to age of intervention.

\begin{tabular}{ccccc}
\hline \multirow{2}{*}{ Visual Acuity } & \multicolumn{4}{c}{ Cataract Age (yrs) } \\
\cline { 2 - 5 } & 0 to 2 & 3 to 5 & 6 to 10 & 11 to 18 \\
\hline Uncooperative & 1 & 6 & 12 & 1 \\
$<1 / 60$ & 5 & 58 & 130 & 160 \\
$1 / 60$ to $3 / 60$ & 3 & 26 & 67 & 102 \\
$6 / 60$ to $6 / 36$ & 0 & 11 & 50 & 54 \\
$6 / 24$ to $6 / 18$ & 81 & 75 & 88 & 73 \\
$6 / 12$ to $6 / 9$ & 0 & 3 & 39 & 46 \\
$6 / 6$ to $6 / 5$ & 2 & 5 & 62 & 139 \\
Total & 92 & 184 & 448 & 575 \\
\hline$P=0.000$. & & & &
\end{tabular}

Table 9. Comparision of visual outcome according to surgical approach.

\begin{tabular}{ccc}
\hline \multirow{2}{*}{ Visual Acuity } & \multicolumn{2}{c}{ Surgical Approach } \\
\cline { 2 - 3 } & A & P \\
\hline Uncooperative & 10 & 10 \\
$<1 / 60$ & 194 & 160 \\
$1 / 60$ to $3 / 60$ & 140 & 59 \\
$6 / 60$ to $6 / 36$ & 92 & 24 \\
$6 / 24$ to $6 / 18$ & 230 & 88 \\
$6 / 12$ to $6 / 9$ & 80 & 9 \\
$6 / 6$ to $6 / 5$ & 193 & 16 \\
Total & 939 & 366 \\
\hline
\end{tabular}

$P=0.000$.
Table 10. Comparision of visual outcome according to PPC.

\begin{tabular}{ccc}
\hline \multirow{2}{*}{ Visual Acuity } & \multicolumn{2}{c}{ PPC } \\
\cline { 2 - 3 } & No & Yes \\
\hline Uncooperative & 12 & 8 \\
$<1 / 60$ & 259 & 95 \\
$1 / 60$ to $3 / 60$ & 108 & 91 \\
$6 / 60$ to $6 / 36$ & 73 & 43 \\
$6 / 24$ to $6 / 18$ & 193 & 125 \\
$6 / 12$ to $6 / 9$ & 63 & 26 \\
$6 / 6$ to $6 / 5$ & 151 & 58 \\
Total & 859 & 446 \\
\hline
\end{tabular}

$P=0.000 ;$ PPC $=$ Primary Posterior Capsulotomy.

Table 11. Comparision of visual outcome according to insertion of IOL.

\begin{tabular}{ccc}
\hline \multirow{2}{*}{ Visual Acuity } & \multicolumn{2}{c}{ IOL } \\
\cline { 2 - 3 } & No & Yes \\
\hline Uncooperative & 1 & 19 \\
$<1 / 60$ & 31 & 323 \\
$1 / 60$ to $3 / 60$ & 17 & 182 \\
$6 / 60$ to $6 / 36$ & 3 & 113 \\
$6 / 24$ to $6 / 18$ & 48 & 270 \\
$6 / 12$ to $6 / 9$ & 2 & 87 \\
$6 / 6$ to $6 / 5$ & 3 & 206 \\
Total & 105 & 1200 \\
\hline$P=0.000$. & &
\end{tabular}

We examined age of intervention and found significantly better outcomes if the intervention was performed at $>5$ years (Table 12; $P<0.001)$. Vision was better at $>5$ years in both groups.

We compared results by morphology of the cataract in non-traumatic group. Good results were achieved with lamellar cataracts (Table 13; $P<0.001$ ).

We examined cases with amblyopia and unilateral as well as bilateral cataracts. A significant difference was found in bilateral cases (Table 14; $P<0.001$ ). In the nontraumatic group, 184 eyes had a unilateral cataract with deprivational amblyopia; vision improvement was not significant (Table 14; $P=0.510$ ).

For the traumatic group, we also gathered data regarding activities at the time of the injury and the object causing the injury (Tables 15 and 16).

\section{Discussion}

The enrolled patient group consisted of 1305 eyes of 805 
Table 12. Comparision of visual outcome amongst I ntervention under and above 5 years.

\begin{tabular}{cccc}
\hline & \multicolumn{2}{c}{ Category } & Total \\
\cline { 2 - 4 } & $\leq 5$ & $>5$ & \\
\hline Uncooperative & 8 & 12 & 20 \\
$<1 / 60$ & 64 & 291 & 353 \\
$1 / 60$ to $3 / 60$ & 29 & 169 & 198 \\
$6 / 60$ to $6 / 36$ & 12 & 105 & 115 \\
$6 / 24$ to $6 / 18$ & 162 & 155 & 317 \\
$6 / 12$ to $6 / 9$ & 4 & 86 & 88 \\
$6 / 6$ to $6 / 5$ & 7 & 201 & 208 \\
Total & 286 & 1019 & 1305 \\
\hline
\end{tabular}

$P=0.000$.

Table 13. Comparative visual outcome in eyes with lamellar catarcat with other morphologies.

\begin{tabular}{cccc}
\hline \multirow{2}{*}{ Post Operative Vision } & \multicolumn{2}{c}{ Morphology } & Total \\
\cline { 2 - 4 } & Other & Lamellar & Other \\
\hline Uncooperative & 12 & 3 & 15 \\
$<1 / 60$ & 139 & 13 & 152 \\
$1 / 60$ to $3 / 60$ & 97 & 32 & 129 \\
$6 / 60$ to $6 / 36$ & 38 & 31 & 69 \\
$6 / 24$ to $6 / 18$ & 151 & 72 & 223 \\
$6 / 12$ to $6 / 9$ & 18 & 17 & 35 \\
$6 / 6$ to $6 / 5$ & 49 & 19 & 68 \\
Total & 504 & 187 & 691 \\
\hline
\end{tabular}

$P=0.000$

pediatric patients. The mean patient age was $9.5 \pm 4.7$ years. The mean age in another report was 7.1 [22]. Age at intervention had a significant effect on visual outcome (Table 4). Other investigators have reported similar findings [23].

There was no overall significant difference in a comparison of procedures with or without primary posterior capsulotomy and vitrectomy (Table 10) [24-26], but a significant difference $(P=0.008)$ was found in the traumatic group. A randomized controlled trial may provide more prcise information regarding this difference.

The anterior approach was superior to the pars plana approach (Table 9; [27-31]. However, the posterior approach was typically selected for more complex conditions.

The incidence of traumatic cataracts in children was higher than that reported previously [32]. In a compari-
Table 14. Comparative visual outcome in unilateral amblyopic eyes.

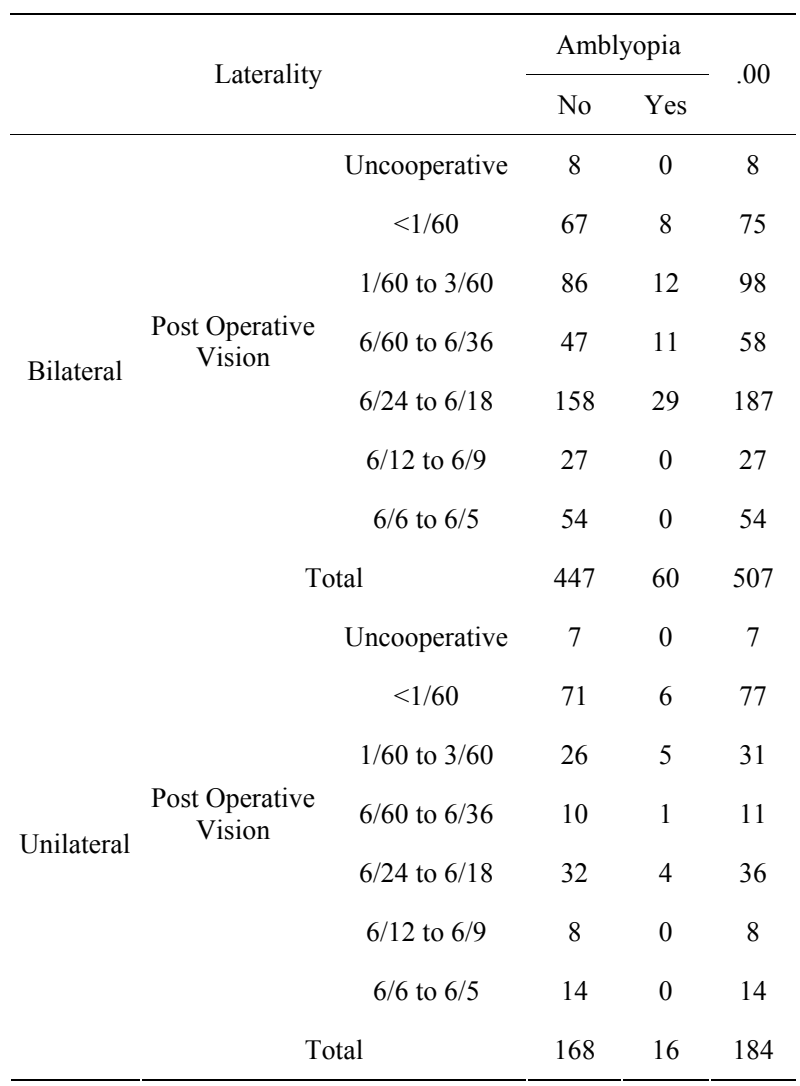

$\mathrm{BL} p=0.008 \mathrm{UL} p=0.510$.

Table 15. Activity at the time of the injury.

\begin{tabular}{cc}
\hline Activities & Percentage (\%) \\
\hline Fall & 1.7 \\
Making a Fire & 2.8 \\
Housework & 16.4 \\
Employment & 5.6 \\
Other & 12.7 \\
Walking & 1.1 \\
Playing & 55.1 \\
Travelling & 3.4 \\
Unknown & 1.1 \\
Total & 100.0 \\
\hline
\end{tabular}

son of the traumatic and non-traumatic groups, the group with traumatic cataracts did significantly better, likely attributable to the fully developed visual system in children above 5 years of age versus children with local or systemic anomalies in cases of congenital or developmental cataracts. With regard to unilateral and bilateral 
Table 16. Object causing the injury.

\begin{tabular}{cc}
\hline Object & Percentage (\%) \\
\hline Ball & 1.4 \\
Cattle Horn & 1.7 \\
Cattle Tail & 0.3 \\
Finger & 0.8 \\
Fire & 2.8 \\
Glass & 1.1 \\
Thorn & 3.4 \\
Other & 8.8 \\
Sharp Object & 8.8 \\
Stone & 10.7 \\
Unknown & 8.8 \\
Stick & 51.4 \\
Total & 100.0 \\
\hline
\end{tabular}

cases, we found that unilateral cataracts did better, in contrast to some other reports (Table 7) [10,33,34], again likely attributable to the large number of traumatic cases.

A prospective study of the outcome of surgery for cataracts in the pediatric age group has several limitations. Although we believe that all patients included in the study had congenital, developmental, or traumatic lens opacities, not all patients were seen and followed by us from the time of birth. In particular, some patients with lamellar cataracts were not seen by us until they were several years old.

Regarding timing of intervention, our study suggests that visual outcome is affected by age of intervention, etiology, and laterality. Traumatic cataracts did well with late interventions (age 11 - 18; Table 3). Patients in the non-traumatic group did well in the case of type 1 morphology if the intervention was early and in the case of type 2 morphology (partial opacity), if the intervention was late. In cases of unilateral cataracts, sooner is better. These findings were similar in the non-traumatic group [10]. For the traumatic group, the interval between injury and intervention is important [35]. On the other hand, their lens opacities were characteristic of congenital lamellar cataracts [10], a type of cataract we have not found to be acquired postnatally in otherwise healthy children.

The surgeries performed in our series of patients were not identical in all cases. For example, the posterior capsule was handled differently at different times during the study period. Additionally, the timing of surgery was not dictated by an established protocol, but was determined by age at the time of referral and by the visual status of individual patients. Finally, some observations that would have been useful for analysis were missing from the records because of loss to follow-up.

Nevertheless, we feel that some useful observations can be made on the basis of this review of patients. There seem to be two general categories of patients with congenital and developmental cataracts. One is characterized by extensive lens opacity and an early, obvious reduction in vision. These patients, who come for cataract surgery in the first year of life, often have smaller-than-normal corneal diameters, poorly dilating pupils, and a vulnerability to delayed postoperative open-angle glaucoma. The other category includes patients with partial, often lamellar lens opacities, corneas of normal size, and a remarkably good visual prognosis. Lamellar cataract did significantly better when compared with other morphologies in the non-traumatic group, similar to other studies (Table 13) [10]. Of the patients in the first category, $222(17 \%)$ developed nystagmus at 2 - 4 months of age, which was accompanied by a reduction in visual acuity despite a good anatomical result from surgery (Table 6). Early surgery, within the time frame indicated in [10], did not appear to stop the development of nystagmus, although some investigators have suggested that this may be so, based on anecdotal experiences with small numbers of patients $[10,18,19]$. It is possible that even earlier surgery than we have done, undertaken in the first few weeks of life, would have a more favourable influence on the development of nystagmus. On the other hand, the nystagmus may be a manifestation of a more general ophthalmic disorder that would not be influenced by the timing of surgery. Further evaluation of this question will require a randomized controlled study, because patient selection could influence the prevalence of nystagmus in any small series of patients, especially if all patients with congenital cataracts, regardless of type, were subjected to early surgery.

Some concern has been raised about the possibility of a higher complication rate following cataract surgery performed in the first 2 months of life, an important concern, but also one based on a prospective study of patients not randomized with regard to the timing of surgery. While it is well-known that deprivational amblyopia is difficult to surmount in patients with unilateral congenital cataracts (Table 14) [10], it is not a major factor in patients with bilateral partial or lamellar opacities, as long as their lens opacities are symmetrical (Table 10).

The visual prognosis in this group of patients, whose surgery is usually performed after 5 years of age, at a time when increasing visual needs begin to exceed the limits imposed by bilateral congenital cataracts, is excellent (Table 13). The only patients in this second general category who fell short of this high expectation were a few who also had the unfortunate combination of nys- 
tagmus and high myopia.

Treatment of strabismic amblyopia following bilateral congenital cataract surgery is useful, although the ocular misalignment is sometimes hard to identify, and the amblyopia may be profound by the time it is recognized [10]. Deprivational amblyopia due to asymmetry of cataracts from the outset is very difficult to reverse, similar to the situation in patients with monocular congenital cataracts. An early start of treatment would seem to be the only hope of success in these asymmetric cases (Table 14) [10].

Development of open-angle glaucoma is a known complication of early cataract surgery; surprisingly, there was no such case in our study. The cause of delayed open-angle glaucoma following congenital cataract surgery is not well-understood [10,34]. It has been suggested that the trabecular meshwork is less porous because of early postoperative inflammation. Another possibility is that there is an underlying developmental abnormality of the anterior chamber angle, predisposing to the glaucoma and related to the developmentally small corneas and poorly dilating pupils that are seen in association with more severe congenital cataracts. The $27 \%$ incidence of delayed open-angle glaucoma in patients who have had surgery in the first 15 months is probably an underestimate, because we do not yet have postoperative pressure measurements in all patients and the glaucoma develops late. Certainly, ocular pressures should be monitored regularly after early congenital cataract surgery. The incidence of glaucoma following later surgery for congenital lamellar opacities was zero in our series [10].

\section{Conclusions}

- Overall, satisfactory results may be achieved.

- Primary IOL has a positive influence in children above 1.5 years.

- Traumatic cataracts have a better prognosis.

- Bilateral cases had a better prognosis.

- Lamellar cataract had a better prognosis.

- Intervention at an early age had a better prognosis in the non-traumatic group, while late intervention [6-18] had a better prognosis in the traumatic group.

\section{REFERENCES}

[1] V. Long and S. Chen, "Surgical Interventions for Bilateral Congenital Cataract," Cochrane Database of Systematic Reviews, Vol. 19, No. 3, 2006, p. CD003171.

[2] M. A. Zimmermann-Paiz and C. R. Quiroga-Reyes, "Pediatric Cataract in a Developing Country: Retrospective Review of 328 Cases," Arquivos Brasileiros de Oftalmologia, Vol. 74, No. 3, 2011, pp. 163-165.

[3] P. Gogate and K. Kalua, "Blindness in Childhood in Developing Countries: Time for a Reassessment," PLoS Me- dicine, Vol. 6, No. 12, 2009, p. e1000177. doi:10.1371/journal.pmed.1000177

[4] M. E. Wilson and S. K. Pandey, "Paediatric Cataract Blindness in the Developing World: Surgical Techniques and Intraocular Lenses in the New Millennium," British Journal of Ophthalmology, Vol. 87, No. 1, 2003, pp. 1419. doi:10.1136/bjo.87.1.14

[5] K. M. de Carvalho and N. Minguini, "Characteristics of a Pediatric Low-Vision Population," Journal of Pediatric Ophthalmology and Strabismus, Vol. 35, No. 3, 1998, pp. 162-165.

[6] W. C. Owens and W. F. Hughes, "Results of Surgical Treatment of Congenital Cataract," Archives of Ophthalmology, Vol. 39, No. 3, 1948, pp. 339-350. doi:10.1001/archopht.1948.00900020346009

[7] G. Msukwa, M. Njuguna, et al., "Cataract in Children Attending Schools for the Blind and Resource Centers in Eastern Africa," Ophthalmology, Vol. 116, No. 5, 2009, pp. 1009-1012. doi:10.1016/j.ophtha.2008.12.020

[8] R. Dandona and L. Dandona, "Review of Findings of the Andhra Pradesh Eye Disease Study: Policy Implications for Eye-Care Services," Indian Journal of Ophthalmology, Vol. 49, No. 4, 2001, pp. 215-234.

[9] A. R. Vasavada, S. A. Vasavada, N. Bobrova, M. R. Praveen, S. K. Shah, V. A. Vasavada, A. J. V. Pardo and S. M. Raj, "Trivedi RH Outcomes of Pediatric Cataract Surgery in Anterior Persistent Fetal Vasculature," Journal of Cataract \& Refractive Surgery, Vol. 38, No. 5, 2012, pp. 849-857. doi:10.1016/j.jcrs.2011.11.045

[10] R. M. Robb and R. A. Petersen, "Outcome of Treatment for Bilateral Congenital Cataracts," Transactions of the American Ophthalmological Society, Vol. 90, 1992, pp. 183-194.

[11] M. Yamamoto, M. Dogru, et al., "Visual Function Following Congenital Cataract Surgery," Japanese Journal of Ophthalmology, Vol. 42, No. 5, 1998, pp. 411-416. doi:10.1016/S0021-5155(98)00039-2

[12] J. Francois, "Late Results of Congenital Cataract Surgery," Ophthalmology, Vol. 86, No. 9, 1979, pp. 15861598 .

[13] D. A. Hiles and P. H. Wallar, "Visual Results Following Infantile Cataract Surgery," International Ophthalmology Clinics, Vol. 17, No. 4, 1977, pp. 265-282.

[14] H. G. Scheie, "Aspiration of Congenital or Soft Cataracts: A New Technique," American Journal of Ophthalmology, Vol. 50, 1960, pp. 1048-1056.

[15] D. Taylor, "Choice of Surgical Technique in the Management of Congenital Cataract," Transactions of Ophthalmological Societies of United Kingdom, Vol. 101, No. 1, 1981, pp. 114-117.

[16] M. M. Parks, "Posterior Lens Capsulectomy during Primary Cataract Surgery in Children," Ophthalmology, Vol. 90, No. 4, 1983, pp. 344-345.

[17] G. L. Rogers, C. L. Tishler, B. H. Tsou, et al., "Visual Acuities in Infants with Congenital Cataracts Operated on Prior to 6 Months of Age," Archives of Ophthalmology, Vol. 99, No. 6, 1981, pp. 999-1003. 
doi:10.1001/archopht.1981.03930010999002

[18] S. S. Gelbart, C. S. Hoyt, G. Jastrebski, et al., "LongTerm Visual Results in Bilateral Congenital Cataracts," American Journal of Ophthalmology, Vol. 93, No. 5, 1982, pp. 615-621.

[19] D. Taylor, Vaegan, J. A. Morris, et al., "Amblyopia in Bilateral Infantile and Juvenile Cataract: Relationship to Timing of Treatment," Transactions of Ophthalmological Societies of United Kingdom, Vol. 99, No. 1, 1979, pp. 170175.

[20] R. H. Trivedi and M. E. Wilson, "Accuracy of the Holladay 2 Intraocular Lens Formula for Pediatric Eyes in the Absence of Preoperative Refraction," Journal of Cataract \& Refractive Surgery, Vol. 37, No. 7, 2011, pp. 1239-1243. doi:10.1016/j.jcrs.2011.01.021

[21] S. K. McClatchey, "Choosing IOL Power in Pediatric Cataract Surgery," International Ophthalmology Clinics, Vol. 50, No. 4, 2010, pp. 115-123. doi:10.1097/IIO.0b013e3181f0f2e0

[22] N. G. Congdon and S. Ruiz, "Determinants of Pediatric Cataract Program Outcomes and Follow-Up in a Large Series in Mexico," Journal of Cataract \& Refractive Surgery, Vol. 33, No. 10, 2007, pp. 1775-1780. doi:10.1016/j.jcrs.2007.06.025

[23] M. L. Yang, C. H. Hou, et al., "Clinical Characteristics and Surgical Outcomes of Pediatric Cataract in Taiwan," Graefe's Archive for Clinical and Experimental Ophthalmology, Vol. 244, No. 11, 2006, pp. 1485-1490. doi:10.1007/s00417-006-0308-4

[24] H. Ahmadieh, M. A. Javadi, et al., "Primary Capsulectomy, Anterior Vitrectomy, Lensectomy, and Posterior Chamber Lens Implantation in Children: Limbal versus Pars Plana," Journal of Cataract \& Refractive Surgery, Vol. 25, No. 6, 1999, pp. 768-775. doi:10.1016/S0886-3350(99)00040-1

[25] D. Thouvenin, "Management of Infantile Cataracts: Surgical Technics and Choices in Lens Implantation," Journal Francais D Ophtalmologie, Vol. 34, No. 3, 2007, pp. 198-202. doi:10.1016/j.jfo.2011.01.003

[26] K. S. Morgan and Z. A. Karcioglu, "Secondary Cataracts in Infants after Lensectomies," Journal of Pediatric Ophthalmology and Strabismus, Vol. 24, No. 4 1987, pp. 4548.

[27] D. Taylor, "Choice of Surgical Technique in the Management of Congenital Cataract," Transactions of Ophthalmological Societies of United Kingdom, Vol. 101, No. 1, 1981, pp. 114-117.

[28] S. Basti and U. Ravishankar, "Results of a Prospective Evaluation of Three Methods of Management of Pediatric Cataracts," Ophthalmology, Vol. 103, No. 5, 1996, pp. 713720.

[29] S. A. Grossman and G. A. Peyman, "Long-term Visual Results after Pars Plicata Lensectomy-Vitrectomy for Congenital Cataracts," British Journal of Ophthalmology, Vol. 72, No. 8, 1988, pp. 601-606. doi:10.1136/bjo.72.8.601

[30] J. J. Kanski and M. D. Crick, "Lensectomy," Transactions of Ophthalmological Societies of United Kingdom, Vol. 97, No. 1, 1977, pp. 52-57.

[31] B. Gessner and S. Wiese, "Results of Pars Plana Lensectomy for Childhood Cataract," Ophthalmologe, Vol. 101, No. 9, 2004, pp. 901-906.

[32] R. Khandekar and A. Sudhan, "Pediatric Cataract and Surgery Outcomes in Central India: A Hospital Based Study," Indian Journal of Medical Sciences, Vol. 61, No. 1, 2007, pp. 15-20. doi:10.4103/0019-5359.29593

[33] P. Hochstrasser and B. Gloor, "Surgical Results of Uniand Bilateral Congenital and Traumatic Cataract in Infancy to Adolescence," Klin Monbl Augenheilkd, Vol. 204, No. 5, 1994, pp. 274-278. doi:10.1055/s-2008-1035534

[34] R. V. Keech and A. C. Tongue, "Complications after Surgery for Congenital and Infantile Cataracts," American Journal of Ophthalmology, Vol. 108, No. 2, 1989, pp. 136141.

[35] M. A. Shah, S. M. Shah, S. B. Shah and U. Patel, "Effect of Interval between Time of Injury and Timing of Intervention on Final Visual Outcome in Cases of Traumatic Cataract," European Journal of Ophthalmology, Vol. 21, No. 6, 2011, pp. 760-765. doi:10.5301/EJO.2011.6482 